\title{
Comparison of Transhiatal and Transthoracic Approaches in Esophageal Cancer Surgery
}

\author{
Orçun Yalav (D), Uğur Topal (D), Burak Yavuz (D), Kubilay Dalcı (1) \\ Department of General Surgery, Çukurova University School of Medicine, Adana, Turkey
}

ORCID IDs of the authors: O.Y. 0000-000I-9239-4I63; U.T. 0000-0003-I305-2056; B.Y. 0000-0002-5262-0346; K.D. 0000-0002-3I56-4269.

Cite this article as: Yalav O, Topal U, Yavuz B, Dalcı K. Comparison of Transhiatal and Transthoracic Approaches in Esophageal Cancer Surgery. Cyprus J Med Sci 2020; 5(I): 66-76.

\section{BACKGROUND/AIMS}

We aimed to compare the efficacy and safety of transthoracic and transhiatal surgical approaches for esophageal cancer in our clinic.

\begin{abstract}
MATERIAL and METHODS
The records of patients who underwent curative resection for esophageal cancer between 2011 and 2019 were retrospectively reviewed Patients were divided into two groups according to the surgical approach: Group I, transhiatal esophagectomy (THE); and Group 2, transthoracic esophagectomy (TTE). Demographics, preoperative stages, intraoperative findings, postoperative morbidity, mortality, and
\end{abstract} mean survival were compared.

\section{RESULTS}

Group I (THE) had II patients and Group 2 (TTE) had 19 patients. The groups were similar in terms of age, sex, and preoperative stage $(p=0.5)$. Surgery duration $(p=0.002)$ and the number of dissected lymph nodes $(p=0.048)$ were significantly higher in the TTE group, but intraoperative blood loss $(p=0.80 \mathrm{l})$, postoperative hospital stay $(p=0.4 \mid 4)$, postoperative complication rates $(p=0.734)$, postoperative mortality ( $p=0.393)$, and mean survival time $(p=0.164)$ were not significantly different between the groups.

\section{CONCLUSION}

Comparing the TTE and THE surgical techniques performed for esophageal cancer in our clinic, the surgery time was longer for TTE, which allowed for more lymph node dissection; however, TTE showed similar morbidity and mortality rates as THE, and the type of surgical approach did not affect postoperative mortality, major morbidity rates, anastomosis complications, length of hospital stay, or survival time. We believe that these results are due to the low number of patients in the study, the fact that more experienced surgeons had performed THE in the first 4 years, and that esophagectomy cases were not performed by a single surgical team in our clinic.

Keywords: Esophageal cancer, transhiatal surgery, transthoracic surgery

\section{INTRODUCTION}

Esophageal carcinoma is the eighth most common cancer worldwide and the sixth most common cause of cancer-related deaths (I). There are two main subtypes of esophageal cancer, and each have distinct epidemiological and biological characteristics: esophageal squamous cell carcinoma (ESCC) and esophageal adenocarcinoma (EAC). There is a high correlation between ESCC and smoking, alcohol abuse, and chronic inflammation; EAC, however, is typically associated with Barrett's metaplasia, gastroesophageal reflux disease, and obesity (2).

Today, esophageal cancer still has a high mortality rate and a poor prognosis, despite improvements in surgical techniques and improved preoperative and postoperative care and conditions. The 5 -year survival rate for all patients is less than $20 \%$ (3).

Treatment of esophageal cancer is with surgery, radiotherapy, chemotherapy, or a combination of all three. Today, the most effective treatment of esophageal cancer can be achieved by surgery $(2,4)$. Various methods are used in the surgical treatment of esophageal cancer, with the Ivor Lewis (transthoracic esophagectomy [TTE]) and Orringer (transhiatal esophagectomy [THE]) methods being the most commonly used. 
Transthoracic Esophagectomy (TTE) is typically performed by laparotomy followed by right thoracotomy and intrathoracic anastomosis (Ivor Lewis procedure), first described in two stages in 1946 (5). THE was first performed by Turner for esophageal carcinoma in 1933 (6). In 1978, Orringer supported THE, claiming that a blunt dissection without thoracotomy was safer and better tolerated than combined transthoracic and abdominal surgery (7).

Although both THE and TTE are accepted surgical techniques for esophageal cancer management, there is controversy in the literature as to which of these techniques is superior (8-I0). Unfortunately, there is as yet no evidence-based optimal surgical approach to esophagectomy (II, 12). There has been, and continues to be, important debate regarding the optimal surgical approach (10, 13-15).

Previous studies in the literature have found that neither the transhiatal nor transthoracic approach altered early postoperative mortality, major morbidity rates, hospital stay, or survival in esophageal cancers (16). In addition, the effect of sex, race, and patient comorbidities on postoperative complications was similar for both esophagectomy types (17).

In the light of these studies, we aimed to compare the results of transhiatal and transthoracic approaches to esophageal cancer in our clinic.

\section{MATERIAL AND METHODS}

Thirty patients who were diagnosed with EAC and ESCC after the histopathological examination of tissue obtained by endoscopic biopsy, taken between January I, 20II and January I, 2019, were included in the study (Ethics Approval number 86/23, dated 08.03.2019 was obtained from the Ethics Committee). Patients with no diagnosis of malignancy, those who underwent palliative surgical treatment, patients under 18 years of age, and patients whose records could not be accessed were excluded from the study. The depth of tumor invasion was evaluated with endoscopic ultrasound in suspected cases. Contrast-enhanced computed tomography (CT) of the thorax and the upper and lower abdomen were performed for staging and positron emission tomography-CT was added to screening tests in suspicious cases.

\section{Main Points:}

- Today, treatment of esophageal cancer needs multidisciplinary treatments, including surgery, radiotherapy, chemotherapy, or a combination of all three. The most effective treatment of esophageal cancer may be achieved by surgery following oncologic treatment.

- The most preferred surgical treatment of esophageal cancer is Ivor Lewis (transthoracic esophagectomy [TTE]) or Orringer (transhiatal esophagectomy [THE]), respectively.

- Thoracotomy is technically difficult, although it provides better oncological results and is superior to the transhiatal approach with higher morbidity.

- The most important determinants of survival are the biological behavior of the tumor and its stage during resection, rather than the type of surgical approach. Therefore, patient treatment should be individualized.
The patients were divided into two groups: Group I, THE; and Group 2, TTE. A common database was created by examining patient files, anesthesia records, and hospital information system records. Using this database, patient information was retrospectively evaluated. Follow-up data were supported by telephone interviews with patients. Demographic characteristics, body mass index (BMI), comorbid diseases, American Society of Anesthesiologists (ASA) score, neoadjuvant treatment status, preoperative laboratory values, tumor localizations (upper I/3 and cervical esophagus, middle $1 / 3$, lower $1 / 3$, gastroesophageal junction, and cardia), and clinical stage were recorded. Surgical technique (open, laparoscopic), duration of surgery, mean blood loss, intraoperative complications, additional organ resection, tumor diameter, histological type and grade, total and metastatic lymph nodes removed, pathological stage, postoperative complications according to the Clavien-Dindo classification (18), respiratory and cardiac complications, wound infection, anastomotic leakage, postoperative hospital stay, 30-day mortality, 90-day unplanned admission to the hospital, long-term anastomotic stenosis, local recurrence or metastasis, mean follow-up, mean survival, and current clinical conditions (exitus, living with metastasis, living disease-free) were compared between the two groups.

Anastomotic leakage was defined as a deterioration in the integrity of the anastomosis as documented by a combination of clinical, radiological, and operative tools.

Wound infection was defined as superficial or deep incisional surgical site infection in the surgical wound according to the definition of the Centers for Disease Control (19).

Unscheduled hospitalization within the first 90 days after discharge was considered as unplanned readmission to the hospital.

We considered unplanned reoperation as a surgical procedure under general, spinal, or epidural anesthesia within 30 days of the index operative procedure for any reason, except for follow-up procedures based on pathology results, in accordance with the American College of Surgeons National Surgical Quality Improvement Program definition (20).

The tumor-node-metastasis (TNM) 2010 or 2016 system was used for tumor staging $(21,22)$.

All patients were informed about the surgical options, and written informed consent was obtained. THE is defined as the open resection of the esophagus performed through the esophageal hiatus and thoracic inlet without thoracotomy. TTE is defined as the open resection of the esophagus employing thoracotomy, including all single-, 2-, and 3-stage procedures, using either a right or left thoracotomy or thoracoabdominal incision $(4,23)$.

The transhiatal or transthoracic approach was used according to the patient's general condition, tumor location, and individual surgeon preference. Both procedures were performed a standard manner as previously described $(5,7)$.

\section{Statistical Analysis}

Data were analyzed using IBM Statistical Package for the Social Sciences for Windows, version 24 (IBM Corp., Armonk, NY, USA). Categorical measurements were summarized as numbers and percentages, and continuous measurements were summarized as means 
and standard deviation (median and minimum-maximum where necessary). Chi-squared or Fisher's tests were used to compare categorical variables. In the comparison of continuous measurements between groups, Student's t-test was used for parameters showing a normal distribution according to the number of variables, and the Mann-Whitney $U$ test was used for parameters not showing a normal distribution. Kaplan-Meier and log-rank tests were used for the survival analysis. Statistical significance was set at 0.05 in all tests.

\section{RESULTS}

The study included 30 patients: II in Group I and 19 in Group 2. The

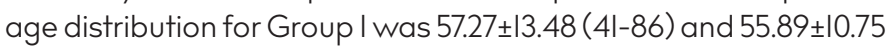
(3l-74) for Group 2 ( $p=0.760$ ). Sex distribution was 5 (45.5\%) men and 6 (54.5\%) women in Group I, and 10 (52.6\%) men and 9 (47.4\%) women in Group 2 ( $p=0.500)$. In Group I, 3 (27.3\%) patients had a score of ASA I, and 8 (72.7\%) patients had ASA 2; whereas in Group 2, 6 (31.6\%) patients had ASA I, 9 (47.3\%) patients had ASA 2 , and $4(21.1 \%)$ patients had ASA $3(p=0.207)$.

The patients' BMI was calculated as 21.63 2.94 (16-26) in Group I and $26.7 \pm 4.4(21-40)$ in Group 2 ( $p=0.005)$. Neoadjuvant treat- ment was administered to I (9.1\%) patient in Group I and 16 (84.2\%) patients in Group 2 ( $p=0.001$ ).

Preoperative hemoglobin levels were II.5 \pm I.7 (8-15) in Group I and

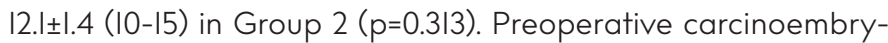
onic antigen (CEA) level was I.0 $\pm 0.8(0-2)$ in Group I and 4.2 \pm 5.8 (0-22) in Group $2(p=0.078)$. Preoperative albumin level was $3.0 \pm 0.4(2-4)$ in Group I and 2.9 $\pm 0.7(2-4)$ in Group 2 ( $p=0.826)$.

The most common presenting symptom was difficulty swallowing in both groups. Nine (8I.I\%) patients in Group I and 14 (73.7\%) patients in Group 2 presented with this symptom ( $p=0.170$ ).

The most common concomitant disease was asthma in Group I, with 3 patients (27.3\%), and diabetes mellitus was observed in 4 $(21 \%)$ patients in Group 2 ( $p=0.078$ ).

The tumor was most commonly located in the lower esophagus in both Group I and Group 2 (54.5\% and 68.4\%, respectively) $(p=0.558)$.

TABLE I. Demographic Characteristics and Preoperative Findings of the Patients

\begin{tabular}{|c|c|c|c|c|}
\hline & & THE n: II & TTE n: 19 & $\mathrm{p}^{*}$ \\
\hline Age (min-max) & & $57.27+13.48(4 \mid-86)$ & $55.89+10.75(31-74)$ & 0.760 \\
\hline Sex & Male & $5(45.5)$ & $10(52.6)$ & 0.500 \\
\hline \multirow[t]{2}{*}{ ASA score } & I & $3(27.3)$ & $6(31.6)$ & 0.207 \\
\hline & 2 & $8(72.7)$ & $9(47.4)$ & \\
\hline BMI (min-max) & & $21.63+2.94(16-26)$ & $24.68+4.25(19-33)$ & 0.045 \\
\hline \multirow[t]{2}{*}{ Neoadjuvant CT } & CRT & I (9.1) & $16(84.2)$ & 0.001 \\
\hline & None & $10(90.9)$ & $3(15.8)$ & \\
\hline Preoperative (Hgb)gr/dl(min-max) & & $11.5+1.7(8-15)$ & $12.1+1.4(10-15)$ & 0.313 \\
\hline \multirow{2}{*}{ Symptom } & Dyspepsia & $0(0.0)$ & $4(21.1)$ & \\
\hline & Swallowing difficulty & $9(81.8)$ & $14(73.7)$ & \\
\hline \multirow[t]{6}{*}{ Concomitant Diseases } & Asthma & $3(27.3)$ & $0(0.0)$ & 0.078 \\
\hline & Diabetes & $0(0.0)$ & $4(21.5)$ & \\
\hline & HT & I (9.1) & $0(0.0)$ & \\
\hline & CAD & $0(0.0)$ & $2(10.5)$ & \\
\hline & COPD & $0(0.0)$ & I (5.3) & \\
\hline & Nephrolithiasis & I (9.1) & $0(0.0)$ & \\
\hline
\end{tabular}


Demographic characteristics and preoperative findings of the patients are shown in Table I.

In Group 2, 3 (I5.8\%) patients underwent anastomosis in the cervical region, whereas in Group l, all patients underwent anastomosis in the cervical region $(p=0.000)$. Laparoscopy-assisted surgery was performed in I (9.1\%) patient in Group I and in $8(42.1 \%)$ patients in Group 2 ( $p=0.065)$. Anastomosis was performed with a stapler in I (9.1\%) patient in Group I and in 6 $36.6 \%$ ) patients in Group 2 ( $p=0.17 \mathrm{l})$. Duration of surgery was $210.0 \pm 36.8$ $\min (150-250)$ in Group I and 321.84 $101.0 \mathrm{~min}$ (|40-540) in Group 2 $(p=0.002)$. Mean blood loss was $210.0 \pm 111.9 \mathrm{~mL}$ (50-350) in Group I and 225.2 $\pm 179.1 \mathrm{~mL}(10-600)$ in Group 2 ( $p=0.80 \mid$ ). No additional organ resection was needed in any patient and no intraoperative complication developed. R0 resection was performed in 9 (81.8\%) patients in Group I and in 15 patients (78.9\%) in Group 2 $(p=0.737)$. Intraoperative features are shown in Table 2.

Tumor diameter was calculated as $3.00 \pm 2.09 \mathrm{~cm}(0-7.0)$ in Group l, and as $2.47 \pm 2.34(0-8.0)$ in Group 2 ( $p=0.543$ ). Histological type was most commonly squamous cell carcinoma in both Group I and Group 2 ( $63.6 \%$ and $63.2 \%$, respectively) ( $p=0.383)$. The most common histologic grade in Group I was grade I, observed in 7 (63.6) patients, and in Group 2 was grade 2, also observed in $7(36.8 \%)$ patients $(p=0.197)$. The most common pathological stage was 3C in Group I (3 patients, 27.3\%), and 0 (7 patients, $36.8 \%$ ) in Group 2 ( $p=0.086)$. Complete pathologic response was observed in 7 of 16 patients receiving neoadjuvant treatment in Group 2 (43.75\%); however, it was not observed in any patients receiving neoadjuvant treatment in Group I. Our pathological complete response rate was $41.6 \%$. The total number of lymph nodes removed was calculated as $13.27 \pm 8.43$ (3-27) in Group I and as 22.58 \pm 10.0 (10-48) in Group 2 ( $p=0.048)$. The number of metastatic lymph nodes was I.45 $\pm 2.2(0-6)$ in Group I and I.05 $\pm 2.8(0-11)$ in Group $2(p=0.687)$. Tumor characteristics are shown in Table 3.

Postoperative respiratory complications occurred in $3(27.3 \%)$ patients in Group I and 7 (36.9\%) patients in Group 2 ( $p=0.412)$.
Cardiac complications were observed in 2 (10.5\%) patients in Group 2, but not in Group I ( $p=0.393)$. Postoperative anastomotic leakage was detected in 2 (18.2\%) patients in Group I and in 4 (21.1\%) patients in Group 2 ( $p=0.620$ ). Wound infection occurred in $3(27.3 \%)$ patients in Group I and in 2 (10.5\%) patients in Group 2 $(p=0.245)$. Vocal cord paralysis did not occur in Group I, whereas it occurred in $3(15.8 \%)$ patients in Group 2 ( $p=0.239)$. The Clavien-Dindo classification was used to categorize postoperative complications (Figure I); according to this classification, 5 (45.5\%) patients in Group I had Grade I, and 6 (31.6\%) patients in Group 2 had Grade II complications ( $p=0.734$ ). Reoperation was performed for anastomotic leakage in I (9.1\%) patient in Group I, for anastomotic leakage in 2 of 3 (I5.8\%) patients in Group 2, and in I patient due to chylous fistula $(p=0.530)$. Duration of hospitalization in the postoperative intensive care unit (ICU) was $5.91 \pm 4.34(1-16)$ days in Group I and 9.58 \pm 12.5 (1-52) days in Group 2 ( $p=0.359)$. Postoperative hospital stay was $18.55 \pm 9.44(8-41)$ days in Group I and 23.42 \pm 18.05 (8-90) days in Group 2 ( $p=0.414$ ). Two patients in Group 2 developed postoperative 30-day mortality, of cardiac and respiratory origin. There was no postoperative mortality in Group I $(p=0.393)$. When the number and reasons of 90 -day readmissions to the hospital were evaluated, 2 of $3(27 \%)$ patients had anastomotic stenosis and I had feeding jejunostomy displacement in Group I, whereas I (5.3\%) patient presented with anastomotic stenosis in Group $2(p=0.126)$. Anastomotic stenosis occurred in $3(27.3 \%)$ patients in Group I and in $5(26.3 \%)$ patients in Group 2 ( $p=0.637)$. Reflux esophagitis occurred in $2(10.5 \%)$ patients in Group 2. Local recurrence in oncologic follow-up was I (9.1\%) in Group I, and I (5.3\%) in Group $2(p=0.607)$. Distant organ metastasis was detected in $2(18.2 \%)$ patients in Group I and in $3(15.8 \%)$ patients in Group 2 ( $p=0.619)$. Perioperative and postoperative clinical outcomes and oncological outcomes are shown in Table 4.

Postoperative survival time was 43.44 \pm 12.68 (18.579-68.318) months in Group I and 36.329 \pm 4.84 (26.842-45.817) months in Group 2 ( $p=0.287)$. The groups in terms of survival are summarized in Table 5 and Figure $2(p=0.168)$.

TABLE 2. Intraoperative Characteristics

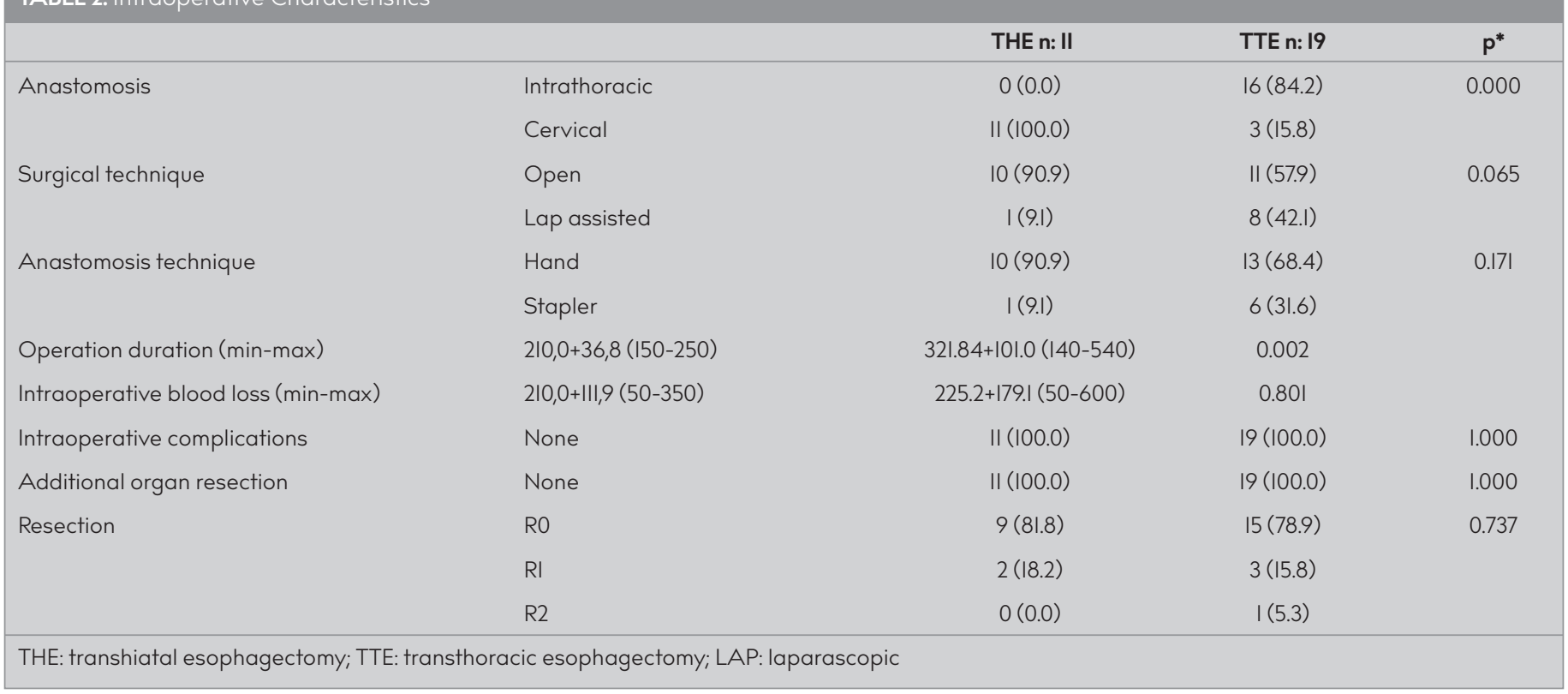




\begin{tabular}{|l|l|}
\hline Degree & \multicolumn{1}{|c|}{ Definitions } \\
\hline I & $\begin{array}{l}\text { Any deviation from the normal postoperative course without the need of intervention } \\
\text { beyond the administration of antiemetics, antipyretics, analgesics, diuretics, electrolytes, } \\
\text { and physical therapy* }\end{array}$ \\
\hline II & $\begin{array}{l}\text { Complications requiring pharmacological treatment with other medicines beyond the ones } \\
\text { used for the complications of degree I }\end{array}$ \\
\hline III & Complications requiring surgical, endoscopic, or radiological intervention \\
\hline III-a & Intervention without general anesthesia \\
\hline III-b & Intervention under general anesthesia \\
\hline IV & Life-threatening complication requiring admission to intensive care unit \\
\hline IV-a & Uni-organ dysfunction (including dialysis) \\
\hline IV-b & Multi-organ dysfunction \\
\hline V & Death \\
\hline
\end{tabular}

*This degree also includes drained cutaneous infections without general anesthesia.

FIGURE I. Classification of surgical complications

\begin{tabular}{|c|c|c|c|c|}
\hline & & THE n: II & TTE n: 19 & $\mathrm{p}^{*}$ \\
\hline Tumor diameter cm (min-max) & & $3.00+2.09(0-7.0)$ & $2.47+2.34(0-8.0)$ & 0.543 \\
\hline & Granular cell tumor & I (9.1) & $0(0.0)$ & \\
\hline & Squamous cell carcinoma & $7(63.6)$ & $12(63.2)$ & \\
\hline & । & $7(63.6)$ & $7(36.8)$ & \\
\hline & 2 & $3(27.3)$ & $4(21.1)$ & \\
\hline & 3 & I (9.1) & $2(10.5)$ & \\
\hline \multirow[t]{4}{*}{ Pathological T } & TO & $0(0.0)$ & $8(42.1)$ & 0.131 \\
\hline & T3 & $3(27.3)$ & $4(21.1)$ & \\
\hline & $\mathrm{T} 4 \mathrm{a}$ & $4(36.4)$ & $3(15.8)$ & \\
\hline & $\mathrm{T} 4 \mathrm{~b}$ & $0(0.0)$ & I (5.3) & \\
\hline \multirow[t]{4}{*}{ Pathological N } & No & $6(54.5)$ & $16(84.2)$ & 0.075 \\
\hline & $\mathrm{NI}$ & $3(27.3)$ & $0(0.0)$ & \\
\hline & N2 & $2(18.2)$ & $2(10.5)$ & \\
\hline & N3 & $0(0.0)$ & I (5.3) & \\
\hline \multirow[t]{2}{*}{ Pathological M } & MO & II (I00.0) & $18(94.7)$ & 0.633 \\
\hline & $\mathrm{Ml}$ & $0(0.0)$ & I (5.3) & \\
\hline \multirow{3}{*}{ Pathological stage } & $3 b$ & $2(18.2)$ & $0(0.0)$ & \\
\hline & $3 c$ & $3(27.3)$ & $2(10.5)$ & \\
\hline & $4 b$ & $0(0.0)$ & I (5.3) & \\
\hline Total dissected lymph nodes (min-max) & & $13.27+8.43(3-27)$ & $22.58+10.0(10-48)$ & 0.048 \\
\hline Metastatic lymph nodes & & $1.45+2.2(0-6)$ & $1.05+2.8(0-11)$ & 0.687 \\
\hline
\end{tabular}




\section{DISCUSSION}

National Comprehensive Cancer Network (NCCN) guidelines for the treatment of esophageal and gastroesophageal cancers (II) and the guidelines of the European Medical Oncology Association (ESMO) for the treatment of esophageal cancer (I2) indicate that primary surgical treatment is essential. Evaluation of the resectability of all esophageal tumors by thoracic and abdominal tomography, positron emission tomography, and endoscopic ultrasound should be evaluated by the esophageal surgeon to determine the feasibility of performing esophagectomy (24).
Accepted surgical procedures in the treatment of esophageal cancer vary. Generally, the two main options are a transabdominal or transthoracic approach. The recommended reconstruction is from a gastric canal if possible, followed by the colon or jejunum. Although the NCCN guidelines (II) do not provide specific advice on the type of esophagectomy to be performed, the ESMO guidelines (12) recommend performing a three-site esophagectomy, the Ivor Lewis type.

There is controversy regarding the optimal surgical approach to the treatment of patients with esophageal cancer. Perceptions

\begin{tabular}{|c|c|c|c|c|}
\hline & & THE n: II & TTE n: 19 & $p^{*}$ \\
\hline \multirow[t]{2}{*}{ Respiratory complications } & No & $8(72.7)$ & $12(63.2)$ & 0.412 \\
\hline & Pneumonia & $2(18.2)$ & $6(31.6)$ & \\
\hline Cardiac complications & No & II (I00.0) & $17(89.5)$ & 0.393 \\
\hline \multirow[t]{2}{*}{ Anastomosis leak } & No & $9(81.8)$ & $15(78.9)$ & 0.620 \\
\hline & Yes & $2(18.2)$ & $4(21.1)$ & \\
\hline \multirow[t]{2}{*}{ Wound complication } & No & $8(72.7)$ & $17(89.5)$ & 0.245 \\
\hline & Yes & $3(27.3)$ & $2(10.5)$ & \\
\hline \multirow{4}{*}{ Complication based on Clavien-Dindo } & 2 & $5(45.5)$ & $5(26.3)$ & \\
\hline & $3 a$ & I (9.1) & $2(10.5)$ & \\
\hline & $3 b$ & $2(18.2)$ & $4(21.1)$ & \\
\hline & 5 & $0(0.0)$ & $2(10.5)$ & \\
\hline \multirow[t]{2}{*}{ Reoperation } & No & $10(90.9)$ & $16(84.2)$ & 0.530 \\
\hline & Yes & I (9.1) & $3(15.8)$ & \\
\hline Postoperative intensive care stay duration (min-max) & & $5,91+4,34(1-16)$ & $9.58+12.5(1-52)$ & 0.359 \\
\hline Postoperative hospital stay duration (min-max) & & $18,55+9,44(8-41)$ & $23.42+18.05(8-90)$ & 0.414 \\
\hline 30-day mortality & No & II (I00.0) & $17(89.5)$ & 0.393 \\
\hline \multirow[t]{2}{*}{ Reflux esophagitis } & No & II (I00.0) & $17(89.5)$ & 0.393 \\
\hline & Yes & $0(0.0)$ & $2(10.5)$ & \\
\hline \multirow[t]{2}{*}{ Local recurrence } & No & $10(90.9)$ & $18(94.7)$ & 0.607 \\
\hline & Yes & I (9.1) & I (5.3) & \\
\hline \multirow[t]{2}{*}{ Metastasis } & No & $9(81.8)$ & $16(84.2)$ & 0.619 \\
\hline & Yes & $2(18.2)$ & $3(15.8)$ & \\
\hline \multirow[t]{3}{*}{ Current state } & Exitus & $7(63.6)$ & $5(26.3)$ & 0.131 \\
\hline & Alive without disease & $3(27.3)$ & II (57.9) & \\
\hline & Alive with metastasis & I (9.1) & $3(15.8)$ & \\
\hline
\end{tabular}

THE: transhiatal esophagectomy; TTE: transthoracic esophagectomy 
of postoperative morbidity and mortality can sometimes lead to surgical treatment, but surgical technique decisions are often based on personal bias, surgeon experience, and ease of the procedure. The ongoing discussion focuses on whether longer resection with thoracotomy provides oncological outcomes superior to resection with relatively limited morbidity and mortality using a transhiatal approach $(14,23)$.

Although the mean age of the patients with esophageal cancer in the meta-analyses ranged from 60 to 66 years, the male sex had significant dominance $(9,17,14)$. The incidence of esophageal cancer increases with age; in one study, $56 \%$ of cases in the UK were patients older than 70 (25). Papenfuss et al. (14) had found the mean age to be greater in patients undergoing the transhiatal approach than those undergoing the transthoracic (66 vs. 63, respectively, $p=0.003$ ) (14). In our series, the age range was younger than in the literature, and in contrast to the series in the literature, the mean age was similar in the groups (57 THE vs. 55 TTE). In our study, although the male sex was more common in the TTE group, there was no significant superiority. There was no statistical difference between the sexes $(p=0.5)$.

In the 4053-case series of Schlottmann et al. (17), $79 \%$ of the patients in the THE group had an ASA score of 3 or more, and $82 \%$ of the TTE group had an ASA score of 3 or more $(p=0.07)$. In the same study, an ASA score $\geq 3$ (odds ratio [OR] I.37; 95\% confidence interval [Cl] I.I3-I.68; $p=0.002$ ) was independently associated with postoperative complications (17). Our series was in agreement with the literature; patients with ASA scores 2 and 3 were the majority, and there was no statistical difference between the groups $(p=0.207)$.

TABLE 5. Survival Time in Terms of Operation Type (Alive)

\begin{tabular}{|lccc|}
\hline & \multicolumn{1}{c|}{$\begin{array}{c}\text { Average } \\
\text { (Mean+sd (Min-Max) }\end{array}$} & $\mathbf{p}$ \\
\hline Operation type & THE & $43.44+12.68(18.579-68.318)$ & 0.164 \\
& TTE & $36.329+4.84(26.842-45.817)$ & \\
\hline \multicolumn{2}{|l}{ THE: transhiatal esophagectomy; TTE: transthoracic esophagectomy } \\
\hline
\end{tabular}

\section{Survival Functions}

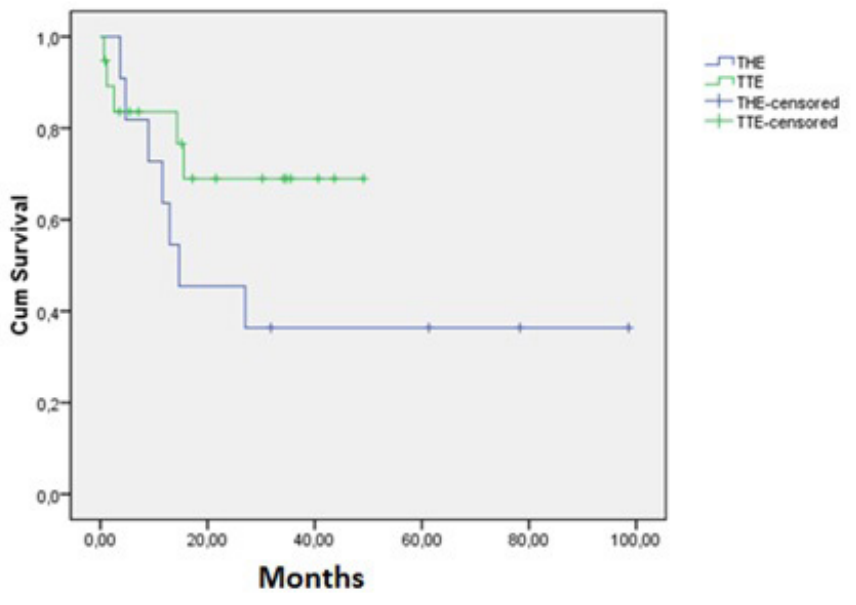

FIGURE 2. Survival duration by group
Although there is not much information in the literature on BMI and surgical method selection, it has been shown that patients with a BMl>23 have better mean survival after esophagectomy, and this parameter is an independent component of predicting survival (26). In our study, BMI was higher in the TTE group compared with the THE group (24 vs. 2l, respectively, $\mathrm{p}=0.045$ ).

It is well known that surgical resection as a monotherapy in esophageal cancer has long been the gold standard, but its usefulness is now being questioned. Neoadjuvant chemotherapy and radiotherapy play an important role in the management of esophageal cancer; in the Chemoradiotherapy for Esophageal Cancer Followed by Surgery Study, patients who underwent surgical treatment after neoadjuvant treatment were compared with patients who only underwent surgical treatment, and a survival advantage was observed in patients receiving neoadjuvant treatment (49.4 vs. 24 months) (27). Esophagectomy is recommended for the initial treatment of patients with TINOMO and T2NOMO tumors, whereas all patients with T3 tumors and some patients with T4a tumors should undergo neoadjuvant chemoradiotherapy (II). In our series, $84 \%$ of the patients in the TTE group received neoadjuvant therapy as initial therapy. The neoadjuvant treatment rate was high in the TTE group $(p=0.00 \mathrm{I})$. Preoperative tumor staging was performed more accurately by using endoscopic ultrasound in tumor staging in our clinic, which led to an increase in neoadjuvant treatment.

Preoperative hemoglobin, albumin, and CEA levels were similar between the groups. Our patients were homogeneous in terms of nutritional status in both groups, as has been previously reported in the literature (16).

Due to the expandable nature of the esophagus, symptoms resulting from an obstructive lesion or stenosis occur only when the tumor has progressed relatively locally or when it reaches a metastatic stage. Warning symptoms include difficulty swallowing, pain during swallowing, and involuntary or progressive weight loss (2). In our series, presenting symptoms were similar between groups, but the most common presenting symptom was difficulty in swallowing.

It is known that patients with higher Charlson Comorbidity Index have a poor prognosis after esophageal cancer surgery, and that comorbid diseases have negative effects on quality of life following esophagectomy $(2,28)$. In the series by Schlottmann et al. (17), comorbid diseases were found to be similar in the TTE and THE groups, with the most common comorbid diseases hypertension and chronic obstructive pulmonary disease (17). In our series, there was no statistical difference between the groups regarding comorbid diseases, as is reported in the literature.

Esophageal tumors can be located in 4 different regions. The behavior of esophageal cancer, treatment modalities, and surgical intervention methods vary. The resection technique depends on tumor location, the natural course of the cancer, and the personal preference of the surgeon. In addition, esophageal cancers differ according to their histological types in their localization (2). In our series, the tumor site was located in the lower and middle esophagus in both groups and there were no differences between the groups. 
In their study comparing cervical and thoracic anastomosis, Biere et al. (29) had found the anastomosis leakage rate and recurrent nerve injury to be higher in patients who underwent esophagectomy with cervical anastomosis (29). In our series, anastomosis was performed in the cervical region in 3 patients in the TTE group.

Minimally invasive esophagectomy has emerged as a viable and safe procedure for esophagectomy in the last few years. It involves hybrid operations that combine laparoscopy with thoracotomy or laparotomy with thoracoscopy and fully minimally invasive procedures or robot-assisted surgeries. A systematic review of 17 studies involving 1598 patients (including minimally invasive surgical combinations) found no difference in long-term survival after minimally invasive surgery compared with open surgery (30). In our series, we performed minimally invasive procedures in $42 \%$ of the patients in the TTE group. Minimally invasive access was determined by the surgeon's preference.

In their 4l6-esophagectomy series, Harustiak et al. (3I) had recommended the stapler technique as an intrathoracic esophagogastric anastomosis method, arguing it led to reduced overall anastomosis leakage and anastomotic stenosis rates compared with the hand-sewn technique. Although we used the stapler technique more often in our anastomoses in the TTE group, there were no statistical differences between the groups.

Papenfuss et al. (17) had found that the duration of surgery in the transthoracic group was increased compared with the transhiatal group (364 vs. 298 min, respectively, $p<0.001$ ) (14). In our series, the surgery time was longer in the TTE group than in the THE group ( 321 vs. 210 min, respectively, $p=0.002$ ). The factors that prolonged the operation time in the TTE group were patients who underwent thoracotomy and minimally invasive procedures.

Blunt dissection of the esophagus during THE can also cause severe intraoperative bleeding. An important contraindication to THE is the presence of excessive fixation in tissues close to the esophagus, such as the membranous trachea or aorta. In addition, both techniques can cause bleeding due to spleen injury during gastric release. Given managing intrathoracic hemorrhage during THE is difficult, patients might need urgent thoracotomy (32). In the series of Zheng B et al. (33), intraoperative bleeding averages was $218.7 \mathrm{~mL}$ in TTE and $202.7 \mathrm{~mL}$ in THE ( $p=0.493$ ). In the meta-analysis by Wei MT et al. (9), no significant difference was found between the two groups (weighted mean difference, $151.17 ; 95 \% \mathrm{Cl}-21.37$ to $323.71 ; \mathrm{p}=0.09$ ). In our series, the amount of intraoperative bleeding was similar ( $225 \mathrm{~mL}$ for THE vs. $210 \mathrm{~mL}$ for TTE, $\mathrm{p}=0.80 \mathrm{I})$. During transhiatal esophagectomy, there was no bleeding that was unexpected or that required thoracotomy.

In our series, no major intraoperative complications were observed to change the course of the operation, and we did not need additional organ resection. Our R0 resection rate was similar between the groups at approximately $80 \%$.

Tumor size is an independent prognostic factor in esophageal cancer as well as an important prognostic factor in many other cancers (34). Zheng B et al. (33) had found tumor diameters to be similar in the TTE and THE groups $(p=0.239)$. In their series, the rate of patients with a tumor diameter of $3 \mathrm{~cm}$ or less was $30 \%$. In our study, the mean tumor diameter was less than $3 \mathrm{~cm}$ in both groups, and there was no statistical difference between the groups. Squamous cell carcinoma was the predominant tumor type in both groups. There was no statistical difference between the groups in terms of tumor stage in the studies in the literature $(10,34)$. In the Khullar OV et al. (I0) series, pathological stage 3 was the most common in both techniques. In our series, the most common stage in the THE group was $3(27.3 \%)$ and in the TTE group was $0(36 \%)(p=0.086)$. Our pathological complete response rate was $43 \%$. Pathological complete response has been reported in the literature to be between $19 \%$ and $33 \%$, and a higher rate of pathological complete response had been found in squamous cell carcinoma (35). This high rate in our series was attributed to the predominant tumor histology of squamous cell carcinoma.

Regarding lymphadenectomy in esophageal cancer, it is important to consider the ways in which this neoplasm spreads. Local regional growth of esophageal cancer is characterized by spread to the submucosal layer. Initially, it spreads to the regional lymph nodes and then to distant lymph nodes and distant organs (24).

In a retrospective study by Peyre et al. (36), they included 2303 patients ( 1381 with EAC and 930 with ESCC) diagnosed with esophageal cancer from 9 international centers undergoing R0 esophagectomy. They found that the mean number of resected lymph nodes was 17. Five-year global survival was $40 \%$, and a Cox regression analysis showed that the number of resected lymph nodes was an independent predictor of survival $(p<0.000 \mathrm{I})$. In this study, no patient received neoadjuvant therapy.

In the series by Khullar et al. (10), the mean difference between lymphadenectomy performed using 2 different techniques had been analyzed, and TTE (II lymph nodes) was found to involve 2 more lymph node resections than THE (9 lymph nodes) ( $p=0.003$ ). Wei et al. (9) had reported 4 articles (2 randomized clinical trials and 2 nonrandomized trials) describing lymphadenectomy in their meta-analysis. They did not find a statistically significant difference in the number of resected nodes in the individualized analysis of both study types (randomized and nonrandomized).

In our study, the number of dissected lymph nodes was statistically higher in the TTE group than in the THE group (22 vs. 12, respectively, $\mathrm{p}=0.048$ ).

The debate on the effect of the operative approach on surgical complications remains ongoing in the twenty-first century. A randomized controlled trial in the Netherlands had shown that THE was associated with fewer pulmonary complications and involved a shorter hospital stay, but there was no significant difference in hospital mortality rates. In the follow-up study of the same cohort, the 5 -year survival for THE and TTE was $34 \%$ and $36 \%$, respectively $(p=0.71)(37,38)$. Boshier et al. (4) had conducted a meta-analysis of 52 studies and reported that the transthoracic group had significantly more respiratory complications and greater early postoperative mortality, and anastomosis leakage was significantly higher in the THE group. 
Theoretically, transthoracic resections have the disadvantages of a thoracotomy, which can result in a greater number of pulmonary complications. Transthoracic resections can be associated with a temporary impairment of respiratory function during left-lateral lung ventilation. The incidence of cardiopulmonary complications can be reduced with modern anesthesia techniques and perioperative respiratory care (39). Pulmonary physiotherapy is important in the early postoperative period in patients undergoing esophagectomy. Schlottmann F et al. (17) had found increased postoperative pulmonary complications in patients who underwent TTE compared to those who received THE. ( $16.8 \%$ vs. $13.8 \%, p=0.001$ ). Although there are studies reporting the rate of postoperative pulmonary complications as similar in the literature $(10)$, the overall rate of pulmonary complications is higher in the TTE group in large metanalyses $(9,17,39)$. Although postoperative pulmonary complications were more common in the TTE group, there was no statistical difference in our series.

In the literature, postoperative cardiac complications after esophagectomy were reported in the range of $2 \%-16 \%$, and there was no difference between TTE and THE groups $(9,10,17$, 39). Our series supports the literature.

The incidence of anastomotic leakage varies widely in the literature (3\%-50\%), which could be due to a problem with the definition of anastomotic leakage: some authors mention only clinically significant leaks, and some accept both subclinical and clinical leaks $(8,9,10,17,33,39)$. The high rate of cervical anastomosis leakage is explained by the reduced blood supply of the proximal gastric area due to the placement of the (tubularized) stomach from the abdomen into the cervical region along a long intrathoracic segment (40). However, it is generally accepted that the mortality rate due to cervical anastomotic leakage is significantly lower than that due to intrathoracic leakages (10). In transthoracic resections, anastomosis can be performed cervically, but it is often performed in the chest. During transhiatal procedures, anastomosis is always performed in the neck.

In their 200I review, Hulscher et al. (39) had found a significant difference in support of transthoracic approaches in general. Wei MT reported in their meta-analysis in 2014 that there was no significant difference between the two groups according to the aggregated results (OR I.24; $95 \% \mathrm{Cl} 0.80$ to $-1.94 ; p=0.34$ ) (9). The effect of the surgical technique on anastomotic leakage has changed over the years. There was no difference between the TTE and THE groups in terms of anastomotic leakage in our series (21.1\% vs. $18.2 \%$ ). In our series, re-exploration was performed in patients with significant leakage, whereas patients with subclinical leakage were followed up medically.

Papenfuss et al. (14) had found in their series that the superficial wound infection rate of the THE group was significantly higher than TTE (II.6\% vs. $6.2 \%, p<0.001$ ). In the Schlottmann F series, the incidence of deep wound infection was significantly higher in THE ( $3.1 \%$ vs. $1.3 \%, p<0.001)(17)$. In our series, in line with the literature, wound complications were more frequent in the THE group than in the TTE group ( $27.3 \%$ and $10.5 \%$, respectively), but there was no statistical difference.
Postoperative continuation of voice hoarseness is a symptom of recurrent laryngeal nerve damage. In the case of superior laryngeal nerve injury, the patient can tolerate solid foods better when oral nutrition is initiated, whereas liquid foods tend to be aspirated. The vocal cord is paralyzed on the anastomosis side. After cervical anastomosis in both the transthoracic and transhiatal procedures, the recurrent nerve was reported to be mainly at risk during cervical dissection and anastomosis (39). In the meta-analysis by Boshier PR et al. (4), the occurrence of vocal cord paralysis had been observed significantly less often after TTE (87 of I54I, 5.6\%) compared with THE (I58 of I448, $10.9 \%$; OR $0.57 ; 95 \% \mathrm{Cl} 0.38-0.84 ; \mathrm{p}=0.005)$. In our series, nerve injury developed in 3 patients in the TTE group: 2 during cervical anastomosis and I during thoracic anastomosis.

Anastomotic leakage has been reported to be a major cause of reoperations after esophageal cancer surgery. In their series, Schlottmann F, etal. (17) found similar reoperation rates in the THE and TTE groups ( $12.1 \%$ vs. $14.1 \%$, p=0.07). In our series, reoperation rates were similar between the groups. Reoperations were due to anastomotic leakage.

Postoperative hospital stay is often considered representative of perioperative complications and as a measure of surgical quality. In the analysis of National Surgical Quality Improvement Program data, Papenfuss et al. (7) had found no difference between TTE and THE in terms of postoperative hospital stay. However, Boshier et al. (4) had found in their meta-analysis an advantage for THE in which hospital length of stay was less than 4 days on average. In the Khullar OV metanalysis, THE was associated with shorter hospital stay than TTE (II.5 vs. I3.0 days, $p<0.006)$. In the same study, THE was associated with a shorter ICU stay compared with TTE ( 5 vs. 7 days, $p<0.006)(10)$. In general, it can be concluded that the hospitalization time in the current cohorts is slightly shorter after THE. In our series, the duration of ICU stay and postoperative hospital stay were shorter in THE group, but no statistical difference was observed. We associated this result with the similarity between postoperative complications and the rates of anastomotic leakage that prolonged hospitalization.

Postoperative mortality after esophageal surgery is typically due to pulmonary complications and anastomotic leakage. Improvements in surgical technique and perioperative care, special anesthesia teams, and interventional radiology assisted implementation of drains have contributed to reduced mortality rates over time (17). In three major meta-analyses comparing transthoracic esophagectomy and transhiatal esophagectomy results, a statistically significant difference was found in perioperative mortality $(9,4,39)$. There was no statistical difference between the two groups in our series. Our causes of mortality were pulmonary complications and sepsis due to anastomotic leakage.

The rate of hospital admissions following esophagectomy for esophageal cancer has previously been reported to be between $5 \%$ and $30 \%(10,41)$.

Admission rates and reoperations after esophageal surgery have a significant impact on hospital costs and quality of care. In addition to mortality, readmission after a surgical procedure is 
increasingly viewed as a sign of quality of care (I0). The Khullar OV series did not find any difference in readmission between the groups. Our series supports the literature, and there was no difference between the groups. Anastomotic leakage has been reported to be the most important risk factor for readmission after esophageal cancer surgery (17). In our series, the reasons for readmission were anastomotic complications.

Anastomotic leakage is a predisposing pathology for stricture development. Patients typically present with dysphagia in the second and third postoperative months. Anastomosis leakage and manual anastomosis are risk factors for stricture development. The rate of anastomosis stenosis after esophagectomy is reported to be 5\%-30\% (32). In the Boshier PR meta-analysis, the rate of anastomosis stenosis had been significantly lower in the TTE group than in the THE group (21.8\% vs. $25.1 \%$; OR $0.58 ; 95 \%$ $\mathrm{Cl} 0.43-0.79 ; p<0.001)$ (4). Although the incidence of anastomotic leakage was higher in cervical anastomosis, benign stricture formation requiring dilatation was not associated with the location of the anastomosis in the meta-analyses (29). In our series, the rate of anastomotic stenosis did not differ between the groups. We preferred endoscopic dilatation for the treatment of anastomotic stenosis.

Local recurrences and distant metastases in esophageal cancer are associated with the tumor's biological structure, histological type, and grade (2). There have been no large meta-analyses comparing the type of surgery with distant metastasis and local recurrence in the literature. In our series, there was no statistical difference between local recurrence and distant metastasis between groups. This result can be explained by the fact that tumor characteristics were similar between groups.

Results after transhiatal and transthoracic surgery showed no difference in overall survival in the meta-analysis of 8 trials (including 3 randomized controlled trials) involving 1155 patients (9). In the series by Khullar OV et al. (10), no difference in 5-year survival was identified (TTE $33.5 \%$ vs. THE $36 \%, p=0.75$ ). In the meta-analysis by Boshier PR et al. (4), an overall analysis of 5 -year survival showed no significant difference between the transthoracic (26.6\%) and transhiatal (25.8\%) groups (OR 1.03; $95 \% \mathrm{Cl} 0.80-1.32 ; \mathrm{p}=0.84)$. Survival in esophageal cancer is affected by many parameters, particularly tumor stage (I3). In our series, the overall survival rates were not affected by the type of surgery, supporting the literature.

In conclusion, TTE and THE can be applied with comparable results for esophageal cancer. Although TTE surgical time is longer, it can be performed with morbidity and mortality rates similar to THE. Lymphadenectomy tends to be more common in transthoracic approaches. We have found that the type of surgical approach for esophageal cancers does not affect postoperative mortality, major morbidity rates, anastomosis complications, length of hospital stay, or survival time. We conclude that the most important determinants of survival are the biological behavior of the tumor and its stage during resection, rather than the type of surgical approach. Therefore, patient treatment should be individualized. The most important limitation of our study was its retrospective nature. Of course, the results of this retrospective clinical analysis should be confirmed by largescale prospective randomized trials.
Ethics Committee Approval: Ethics committee approval was received for this study from the Ethics Committee of Cukurova University. (08.03.2019 $-86 / 23$ ).

Informed Consent: Due to the retrospective design of the study, informed consent was not taken.

Peer-review: Externally peer-reviewed.

Author contributions: Concept-O.Y., U.T.; Design - O.Y., U.T., B.Y., K.D.; Supervision- O.Y., K.D.; Resource:- O.Y., B.Y.; Materials O.Y., K.D.; Data Collection and/or Processing- U.T.B.Y.; Analysis and/or Interpretation- O.Y.,K.D.; Literature Search- O.Y., U.T., B.Y., K.D.; Writing- U.T.; Critical Reviews- O.Y., K.D.

Conflict of Interest: The authors have no conflicts of interest to declare.

Financial Disclosure: The authors declared that this study has received no financial support.

\section{REFERENCES}

I. Arnold M, Soeriomataram I, Ferlay J, Forman D. Global incidence of oesophageal cancer by histological subtype in 2012. Gut 2015; 64(3): 38I-7. [CrossRef]

2. Smyth EC, Lagergren J, Fitzgerald RC, Lordick F, Shah MA, Lagergren P, et al. Oesophageal cancer. Nat Rev Dis Primers 20I7; 3: 17048. [CrossRef]

3. Siegel R, Ma J, Zou Z, Jemal A. Cancer statistics, 2014. CA Cancer J Clin 2014; 64(I): 9-29. [CrossRef]

4. Boshier PR, Anderson O, Hanna GB. Transthoracic versus transhiatal esophagectomy for the treatment of esophagogastric cancer: a meta-analysis. Ann Surg 20ll; 254(6): 894-906. [CrossRef]

5. Lewis I. The surgical treatment of carcinoma of the oesophagus: with special reference to a new operation for growths of the middle third. Br J Surg 1946; 34: 18-31. [CrossRef]

6. Turner GG. Excision of thoracic esophagus for carcinoma with construction of extrathoracic gullet. Lancet 1933; 222(5754): I315-I6. [CrossRef]

7. Orringer MB, Sloan H. Esophagectomy without thoracotomy. J Thorac Cardiovasc Surg 1978; 76(5): 643-54. [CrossRef]

8. Heger P, Blank S, Gooßen K, Nienhüser H, Diener MK, Ulrich A, et al. Thoracoabdominal versus transhiatal surgical approaches for adenocarcinoma of the esophagogastric junction-a systematic review and meta-analysis. Langenbecks Archives Surg 2019; 404(1): 103-13. [CrossRef]

9. Wei MT, Zhang YC, Deng XB, Yang TH, He YZ, Wang ZQ. Transthoracic Vs transhiatal surgery for cancer of the esophagogastric junction: A meta-analysis. World J Gastroenterol 2014;20(29): 10183-92. [CrossRef]

10. Khullar OV, Jiang R, Force SD, Pickens A, Sancheti MS, Ward K et al. Transthoracic versus transhiatal resection for esophageal adenocarcinoma of the lower esophagus: A value-based comparison. J Surg Oncol 2015;112(5): 517-23. [CrossRef]

II. National Comprehensive Cancer Network. Esophageal and esophagogastric junction cancers version 2. NCCN Clin Pract Guidel Oncol 2018.

12. Stahl M, Mariette C, Haustermans K, Cervantes A, Arnold D. Oesophageal cancer: ESMO clinical practice guidelines for diagnosis, treatment and follow-up. Ann Oncol 20l3; 24 Suppl 6: vi5l-6. [CrossRef]

13. Chang AC, Ji H, Birkmeyer NJ, Orringer MB, Birkmeyer J. Outcomes after transhiatal and transthoracic esophagectomy for cancer. Ann Thorac Surg 2008; 85(2): 424-29. [CrossRef]

14. Papenfuss WA, Kukar M, Attwood K, Kakarla VR, Chousleb S, Hochwald SN, et al. Transhiatal versus transthoracic esophagectomy for esophageal cancer: A 2005-20II NSQIP comparison of modern multicenter results. J Surg Oncol 2014; IIO(3): 298-30I. [CrossRef] 
15. Kutup A, Nentwich MF, Bollschweiler E, Bogoevski D, Izbicki JR, Hölscher $\mathrm{AH}$. What should be the gold standard for the surgical component in the treatment of locally advanced esophageal cancer: Transthoracic versus transhiatal esophagectomy. Ann Surg 2014; 260(6): 1016-22. [CrossRef]

16. Oymacı E, Dalgıç T, Keçe C, Demirbağ AE, Bostancı EB, Akoğlu M. The Effects of Transhiatal and Transthoracic Approaches on Mortality, Morbidity, Hospital Stay and Survey in the Surgical Treatment of Esophageal Cancer. Turkiye Klinikleri J Gastroenterohepatol 2012; 19(I): I-8.

17. Schlottmann F, Strassle PD, Patti MG. Transhiatal vs. Transthoracic Esophagectomy: A NSQIP Analysis of Postoperative Outcomes and Risk Factors for Morbidity. J Gastrointest Surg 2017; 2I(II): 175763. [CrossRef]

18. Dindo D, Demartines N, Clavien PA. Classification of surgical complications: a new proposal with evaluation in a cohort of 6336 patients and results of a survey. Ann Surg 2004;240 (2): 205-13. [CrossRef]

19. American College of Surgeons. User Guide for the 2012 ACS NSQIP Participant Use Data File 2013.

20. Horan TC, Gaynes RP, Martone WJ, Jarvis WR, Emori TG. CDC definitions of nosocomial surgical site infections, 1992: a modification of $\mathrm{CDC}$ definitions of surgical wound infections. Am J Infect Control 1992; 13(I0): 606-8. [CrossRef]

21. Edge SB, Byrd DR, Compton CC, Fritz AG, Greene FL, Trotti A, editors. AJCC cancer staging manual (7th ed). New York, NY: Springer; 2010.

22. Hortobagyi GN, Connolly JL, Edge SB. Breast. In: Amin MB, Edge S, Greene G, editors. AJCC Cancer Staging Manual. 8th ed. New York, NY: Springer International Publishing; 2016. [CrossRef]

23. Takahashi C, Shridhar R, Huston J Meredith, K. Esophagectomy from then to now. J Gastrointest Oncol 2018; 9(5): 903-909. [CrossRef]

24. Clemente-Gutiérrez U, Medina-Franco H, Santes O, Morales-Maza J, Alfaro-Goldaracena A, Heslin MJ. Open surgical treatment for esophageal cancer: transhiatal vs. transthoracic, does it really matter?. Journal of Gastrointestinal Oncology 2019; 10(4): 783-8. [CrossRef]

25. Cancer Research UK. Oesophageal cancer statistics. Cancer Research UK. 2017. Available from: URL: http://www.cancerresearchuk.org/ health-professional/cancer-statistics/statistics-by-cancer-type/oesophageal-cancer

26. Ji W, Zheng W, Li B, Cao C, Ma W. Influence of body mass index on the long-term outcomes of patients with esophageal squamous cell carcinoma who underwent esophagectomy as a primary treatment: a 10-year medical experience. Medicine $2016 \mathrm{Jul}$; 95(29): e4204. [CrossRef]

27. Shapiro J, Van Lanschot JJB, Hulshof MC, van Hagen P, van Berge Henegouwen, MI, Wijnhoven BP et al. Neoadjuvant chemoradiotherapy plus surgery versus surgery alone for oesophageal or junctional cancer (CROSS): long-term results of a randomised controlled trial. Lancet Oncol 2015; 16(9): 1090-8. [CrossRef]

28. Backemar L, Wikman A, Djarv T, Johar A, Lagergren P. Comorbidity after oesophageal cancer surgery and recovery of health-related quality of life. Br J Surg 2016; 103(12): 1665-75. [CrossRef]
29. Biere SS, Maas KW, Cuesta MA, and van der Peet DL. Cervical or thoracic anastomosis after esophagectomy for cancer: a systematic review and meta-analysis. Dig Surg 20II; 28(I): 29-35. [CrossRef]

30. Dantoc MM, CoxMR, Eslick GD. Does minimally invasive esophagectomy (MIE) provide for comparable oncologic outcomes to open techniques? A systematic review. J Gastrointest Surg 2012; 16(3): 486-94. [CrossRef]

31. Harustiak T, Pazdro A, Snajdauf M, Stolz A, Lischke R. Anastomotic leak and stricture after hand-sewn versus linear-stapled intrathoracic oesophagogastric anastomosis: single-centre analysis of 415 oesophagectomies. Eur J Cardiothorac Surg 2016; 49(6): 1650-9. [CrossRef]

32. Bașoğlu A. Transhiatal esophagectomy. J Exp Clin Med 2013; 29(4) 243-49. [CrossRef]

33. Zheng B, Chen YB, Hu Y, Wang JY, Zhou ZW, Fu JH. Com parison of transthoracic and transabdominal surgical approaches for the treatment of adenocarcinoma of the cardia. Chin J Cancer 20I0; 29(8): 747-5I. [CrossRef]

34. Wang BY, Goan YG, Hsu PK, Hsu WH, Wu YC. Wu Tumor length as a prognostic factor in esophageal squamous cell carcinoma. Ann Thorac Surg 20II; 9I(3): 887-93. [CrossRef]

35. Blum Murphy M, Xiao L, Patel VR, Maru DM, Correa AM, G Amlashi $F$, et al. Pathological complete response in patients with esophageal cancer after the trimodality approach: the association with baseline variables and survival-The University of Texas MD Anderson Cancer Center experience. Cancer 2017;123(21): 4I06-13. [CrossRef]

36. Peyre CG, Hagen J, DeMeester SR, Altork NK, Ancona E, Griffin $\mathrm{SM}$, et al. The number of lymph nodes removed predicts survival in esophageal cancer: An international study on the impact of extent of surgical resection. Ann Surg 2008; 248(4): 549-56. [CrossRef]

37. Omloo JM, Lagarde SM, Hulscher JB, Reitsma JB, Fockens P, van Dekken $\mathrm{H}$, et al. Extended transthoracic resection compared with limited transhiatal resection for adenocarcinoma of themid/distal esophagus: five-year survival of a randomized clinical trial. Ann Surg 2007; 246(6): 992-1000. [CrossRef]

38. Hulscher JB, van Sandick JW, de Boer AG, Wijnhoven BP, Tijssen JG, Fockens $\mathrm{P}$, et al. Extended transthoracic resection compared with limited transhiatal resection for adenocarcinoma of the esophagus. N Engl J Med 2002; 347(21): 1662-69. [CrossRef]

39. Hulscher, JB, Tijssen JG, Obertop H, van Lanschot JJB. Transthoracic versus transhiatal resection for carcinoma of the esophagus: a meta-analysis. Ann Thorac Surg 2001: 72(1); 306-13. [CrossRef]

40. Bolton JS, Fuhrman GM. Transhiatal Esophagectomy for Carcinoma of the Thoracic Esophagus, In: Wanebo HJ, editor. Surgery for Gastrointestinal Cancer. A Multidisciplinary Approach. LippincottRaven, New York. 1997, pp. 229-240.

4l. Li C, Ferri LE, Mulder DS, Ncuti A, Neville A, Lee L, et al. An enhanced recovery pathway decreases duration of stay after esophagectomy. Surgery 2012; 152(4): 606-14. [CrossRef] 